\title{
Therapeutics
}

\section{Cognitive behaviour therapy was more effective than interpersonal psychotherapy for bulimia nervosa}

Agras WS, Walsh BT,Fairburn CG, et al. A multicenter comparison of cognitive-behavioral therapy and interpersonal psychotherapy for bulimia nervosa. Arch Gen Psychiatry 2000 May;57:459-66.

QUESTION: What is the comparative effectiveness of cognitive behavioural therapy (CBT) and interpersonal psychotherapy (IPT) for the treatment of bulimia nervosa?

\section{Design}

Randomised \{allocation concealed $*\}$, blinded (outcome assessors)*, controlled trial with 1 year of follow up.

\section{Setting}

2 outpatient treatment centres, California and New York, USA.

\section{Patients}

220 women (mean age 28 y, $77 \%$ white, mean body mass index $23 \mathrm{~kg} / \mathrm{m}^{2}$ ) satisfying DSM-III-R criteria for bulimia nervosa. Exclusion criteria were severe physical or psychiatric conditions, current anorexia nervosa, current psychotherapy, use of psychotropic drugs, pregnancy, or previous CBT or IPT. 69\% of patients completed the study, and all patients were included in the intention to treat analysis.

\section{Intervention}

After stratification for history of anorexia nervosa, 110 patients were allocated to CBT, which focused on treating the eating disorder and associated cognitive disturbances, and 110 were allocated to IPT, which focused on achieving interpersonal change. Patients were given 19 individual sessions over a 20 week period. An independent quality control centre (Oxford, UK) trained and supervised the therapists and assessors to ensure similarity across treatments and assessments.

\section{Main outcome measures}

Eating disorder related symptoms and psychopathology.

\section{Main results}

Analysis was by intention to treat. At the end of treatment (20 wks), more patients who received CBT recovered $(p<0.001)$, remitted $(p=0.003)$, and met community norms for eating attitudes and behaviours $(p=0.04)$ than did those who received IPT (table); no difference existed between groups for these outcomes at 1 year.

\section{Conclusions}

In the short term, cognitive behavioural therapy (CBT) was more effective than interpersonal psychotherapy (IPT) for achieving recovery and remission from bulimia nervosa. At 1 year, results from CBT and IPT were equivalent. Although IPT is effective, it takes longer to produce clinical change.

*See glossary.

$\dagger$ Information provided by author.
Cognitive behavioural therapy $(C B T)$ v interpersonal psychotherapy (IPT) for bulimia nervosa:

\begin{tabular}{|c|c|c|c|c|}
\hline $\begin{array}{l}\text { Outcomes at } \\
20 \text { weeks }\end{array}$ & CBT & IPT & $\mathrm{RBI}(95 \% \mathrm{Cl})$ & NNT (Cl) \\
\hline Recovery & $29 \%$ & $6 \%$ & $357 \%$ (118 to 882$)$ & 4 (3 to 8$)$ \\
\hline Remission & $48 \%$ & $28 \%$ & $71 \%(21$ to 145$)$ & $5(3$ to 14$)$ \\
\hline $\begin{array}{l}\text { Normal eating } \\
\text { attitudes and } \\
\text { behaviours }\end{array}$ & $41 \%$ & $27 \%$ & $50 \%$ (3 to 120$)$ & 7 (4 to 92$)$ \\
\hline
\end{tabular}

\section{COMMENTARY}

This 2 centre trial by Agras et al comparing CBT with IPT for the treatment of bulimia nervosa confirms the results of a previous study by Fairburn $e t a l$, which suggested that IPT may have therapeutic results equivalent to $\mathrm{CBT} .^{12}$

The present study was a meticulously designed, controlled trial that allowed the authors to address important issues about the treatment of choice for bulimia nervosa.

The most critical message of this study is that although CBT and IPT lead to similar levels of clinical change at 1 year (and thus can be judged to be equally effective at $1 \mathrm{y}$ ), CBT must be considered to be a superior first line treatmen by virtue of its more rapid effect on symptom reduction.

A rapid clinical improvement is an important dimension on which to base clinical decisions. Provided that a rapid treatment response is not transient, which in the case of CBT for bulimia nervosa it is clearly not, then CBT emerges as the clear winner. Many of the behaviours associated with bulimia nervosa can be physically damaging. In addition, with time, bulimic behaviors become more entrenched, and well worn behavioural patterns can be difficult to break. This study shows that by choosing CBT as a first line treatment, the duration of a patient's exposure to bulimic behaviours can potentially be minimised.

2 important questions remain. Firstly, how can we best approach those patients who did not achieve recovery or remission from CBT? Would IPT be a reasonable second choice for non-responders? Secondly, given that this study further establishes CBT as the psychotherapeutic treatment of choice for bulimia nervosa, how can we improve efforts to disseminate cognitive behavioural techniques to therapists in non-research settings to maximise the number of afflicted patients who receive this preferred treatment? Cynthia M Bulik, $\mathrm{PhD}$ Virginia Commonwealth University Richmond, Virginia, USA

1 Fairburn CG, Jones R, Peveler RC, et al. Three psychological treatments for bulimia nervosa. A comparative trial. Arch Gen Psychiatry 1991;48:463-9.

2 Fairburn CG, Jones R, Peveler RC, et al. Psychotherapy and bulimia nervosa. Longer-term effects of interpersonal psychotherapy, behavior therapy, and cognitive behavior therapy. Arch Gen Psychiatry 1993;50:419-28.
Sources of funding: National Institute of Mental Health; Wellcome Trust; Henry J Kaiser Family Foundation; Foundation Fund for Research in Psychiatry.

For correspondence: Dr W S Agras, Department of Psychiatry and Behavioral Sciences, Stanford University School of Medicine, 401 Quarry Road,

Stanford, CA 94305 ,

USA.Fax +1650723 9807. 


\section{OTHER ARTICLES NOTED}

The journals that are reviewed and the criteria for selecting articles from these journals for inclusion in Evidence-Based Mental Health are set out in the purpose and procedure in each issue. All articles that meet our criteria in the reviewed journals are cited in Evidence-Based Mental Health, but there is not enough space to abstract them all. The following articles passed all criteria but were not abstracted because, in the judgment of the editors, their findings were less widely applicable to clinical practice in the area of mental health.

\section{Therapeutics}

Zuclopenthixol decanoate for schizophrenia and other serious mental illnesses. (Cochrane Review, latest version 25 May 1999). Coutinho E, Fenton M. Quaraishi S. In: Cochrane Library. Oxford: Update Software.

The effects of atypical antipsychotic drugs on neurocognitive impairment in schizophrenia: a review and meta-analysis. Keefe RSE, Silva SG, Perkins DO, et al. Schizophr Bull 1999;25:201-22.

Depot fluspirilene for schizophrenia. (Cochrane Review, latest version 25 May 1999). Quaraishi S, David A. In: Cochrane Library. Oxford: Update Software.

Depot pipothiazine palmitate and undeclynate for schizophrenia. (Cochrane Review, latest version 26 May 1999). Quaraishi S, David A. In: Cochrane Library. Oxford: Update Software.

Depot bromperidol decanoate for schizophrenia. (Cochrane Review, latest version 26 May 1999). Quaraishi S, David A, Adams CE. In: Cochrane Library. Oxford: Update Software.

Depot perphenazine decanoate and enanthate for schizophrenia. (Cochrane Review, latest version 26 May 1999). Quaraishi S, David A. In: Cochrane Library. Oxford: Update Software.

Evidence of clozapine's effectiveness in schizophrenia: a systematic review and meta-analysis of randomized trials. Wahlbeck $\mathrm{K}$, Cheine M, Essali A, et al. Am J Psychiatry 1999 Jul;156:990-9.
Pharmacologic treatment of depression during pregnancy. Wisner KL, Gelenberg AJ, Leonard H, et al. JAMA 1999 Oct;282:1264-9.

\section{Prognosis}

Preterm birth and intra-uterine growth retardation among children of women with schizophrenia. Bennedsen BE, Mortensen PB, Olesen AV, et al. Br J Psychiatry 1999 Sep;175:239-45.

\section{Aetiology}

Predictors of mortality in patients with Alzheimer's disease living in nursing homes. Gambassi G, Landi F, Lapane KL, et al.J Neurol Neurosurg Psychiatry 1999 Jul;67:59-65.

Posttraumatic stress disorder in abused and neglected children grown up. Widom CS. Am J Psychiatry 1999 Aug;156:1223-9.

\section{Economics}

Prescription of transdermal nicotine patches for smoking cessation in general practice: evaluation of cost-effectiveness. Stapleton JA, Lowin A, Russell MAH. Lancet 1999 Jul 17;354:210-5.

\section{Corrections}

In Evidence-Based Mental Health November 1999 on page 105 the journal name for the Barkham et al article should read J Consult Clin Psychol.

Also in the November 1999 issue the formula for calculating the NNT using the PEER and OR found in the glossary should read:

$$
\mathrm{NNT}=\frac{1-[\text { PEER } \times(1-\mathrm{OR})]}{(1-\mathrm{PEER}) \times \mathrm{PEER} \times(1-\mathrm{OR})}
$$

The editorial team apologises for these errors. 